\title{
Bandwidth Enhancement of Pin Shorted Triangular Patch Antenna with Circular Notch
}

\author{
Rajarshi Sanyal \\ Asst. Professor \\ M.C.K.V.I.E \\ Howrah, India
}

\author{
Rajeev Kr. Singh \\ Student(B.Tech-ECE Dept.) \\ M.C.K.V.I.E \\ Howrah, India
}

\author{
Poulami Mahata \\ Student (B.Tech-ECE Dept.) \\ M.C.K.V.I.E \\ Howrah, India
}

\begin{abstract}
This paper presents the notch loading effect on the pin shorted equilateral triangular shaped microstrip antenna (ETMSA). The proposed antenna shows the dual band behavior due to pin shorting and also the effect of circular notch for bandwidth enhancement, with dual shorting pin. The proposed antenna providing enhanced impedance bandwidth of $13.42 \%$.Also effect of different dielectric on the bandwidth performance has been studied. All the results have been carried out using MOM based IE3D simulation.
\end{abstract}

\section{Keywords}

ETMSA, shorting pin, dual band, circular notch.

\section{INTRODUCTION}

In modern wireless communication technology, the demand of compact low profile antenna is increasing significantly. To meet this requirement microstrip antenna has been proposed [1].However conventional microstrip antenna suffers from narrow bandwidth problem [2]. Several well-known methods used for improvement of bandwidth such as, use of thick substrate, different type of slotting like square-ring slot [3], Utype slot [4] etc. The stub loading is also effective bandwidth enhancement technique [5]. Various types of defective ground structuresare also used for bandwidth enhancement of MSA [6].The broad bandwidth can be achieved by using multiple stacked radiation patches with different length [7]. The main aim of this paper is to present the bandwidth enhancement of compact ETMSA using two shorting pin loading with a circular notch.

\section{ANTENNA DESIGN AND}

\section{SIMULATED RESULS}

Basic parameters of ETMSA are $\varepsilon_{\mathrm{r}}=3.2 ; \mathrm{h}=1.6 \mathrm{~mm}, \tan \delta$ $=0.001$ and length of each arm of ETMSA $=20 \mathrm{~mm}$ is taken. The co-axial feed is at $(0,0)$, Which shows the resonant frequency of $5.249 \mathrm{GHz}$ as shown in fig.1a and fig.1b.The percentage bandwidth is equal to $1 \%$ for $-10 \mathrm{~dB}$ return loss. The corresponding directive gain is shown infig.1c. The gain value is $6.806 \mathrm{dbi}$ (approx.).Simulation has been done by the method of moment based IE3D EM Design System (V: 14) simulator [8].

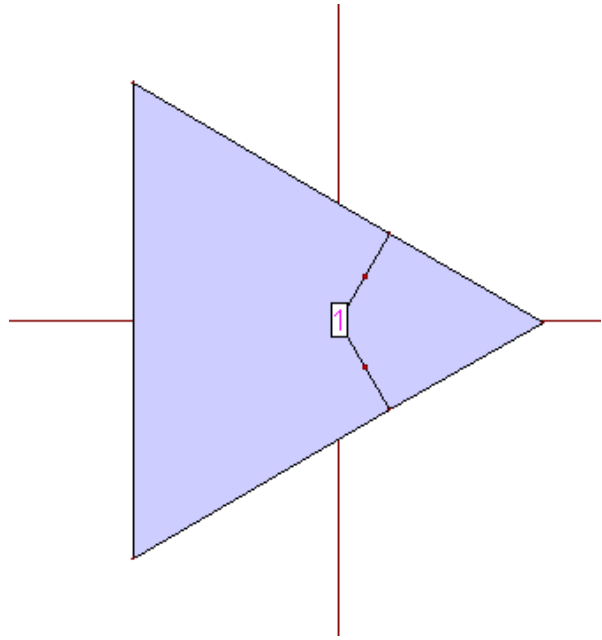

Figure 1a: IE3D Simulated View patch without pin shorting.

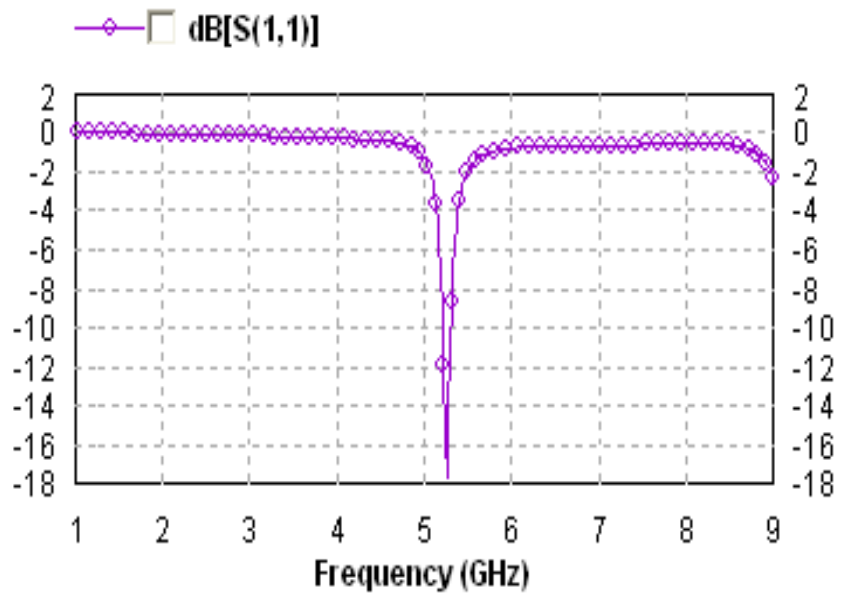

Figure 1b: Return Loss Performance. 


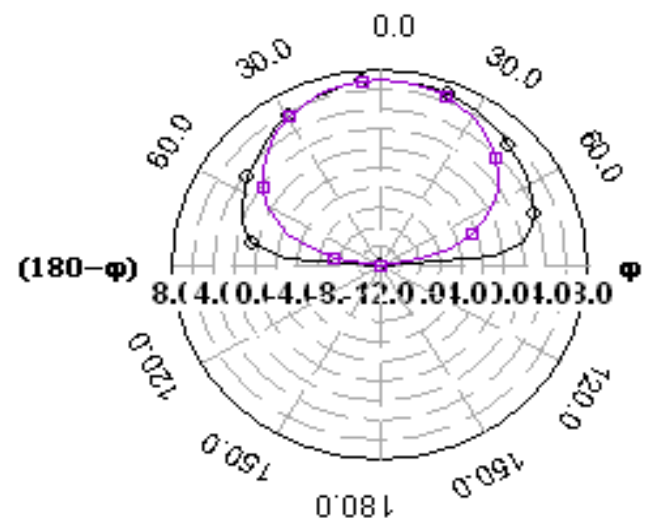

Elevation Pattern Directivity Display (dBi)

Figure 1c: Radiation pattern at $\mathrm{f}=5.249 \mathrm{GHz}$

\subsection{EFFECT OF SINGLE PIN SHORTING}

When Pin $(\mathrm{P} 1)$ is shorted between vertex and co-axial feed point as shown in fig.2a.the resonant frequency shifted from $5.249 \mathrm{GHz}$ to $6.9 \mathrm{GHz}$ as shown in fig. $2 \mathrm{~b}$.In proposed antenna the position of $\mathrm{P} 1$ from vertex is $1.65 \mathrm{~mm}$. The corresponding directive gain is $7.824 \mathrm{dbi}$ as shown in fig.2cAlso, the impedance bandwidth becomes higher (7.2\%), as shown in table (1).

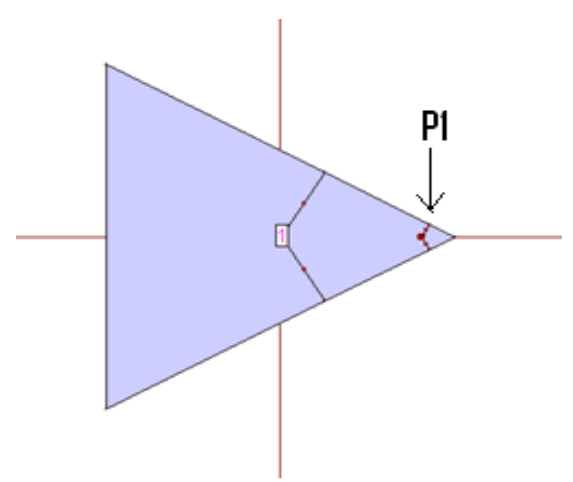

Figure 2a: Effect of single Pin shorting.

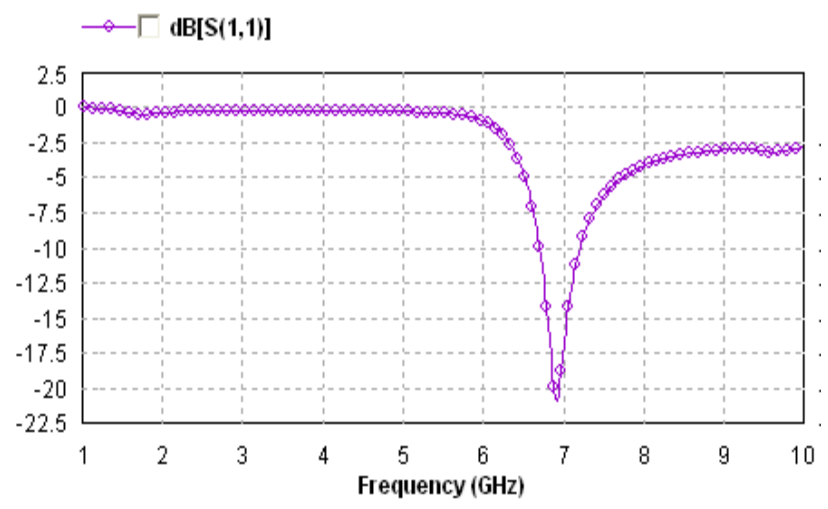

Figure 2b: Return Loss Performance for single pin shorting.
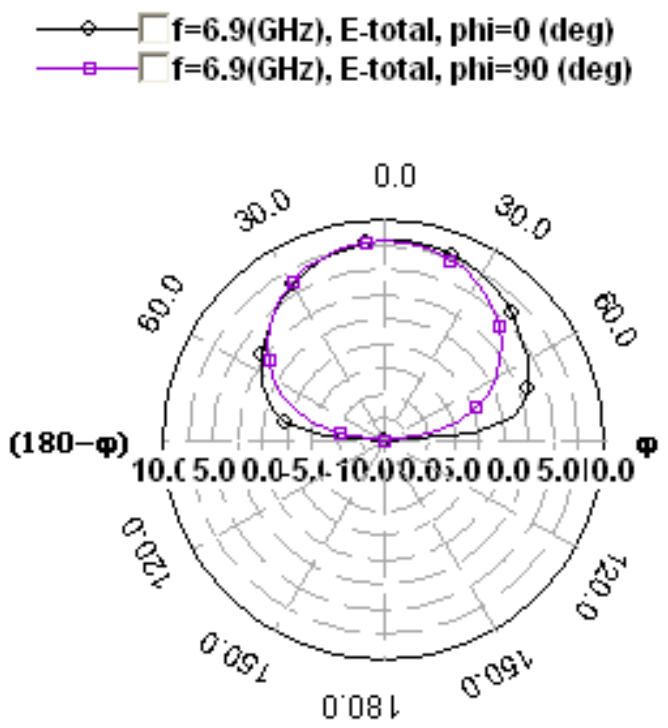

Elevation Pattern Directivity Display (dBi)

Figure 2c: Radiation pattern at $\mathrm{f}=6.9 \mathrm{GHz}$

Table: 1

\begin{tabular}{|c|c|c|c|}
\hline Pin effect & fc $(\mathrm{GHz})$ & $\begin{array}{c}\text { Return loss } \\
(\mathrm{dB})\end{array}$ & $\begin{array}{c}\% \mathrm{~B} . \mathrm{W} . \\
(\mathrm{GHz})\end{array}$ \\
\hline Without Pin & 5.25 & -16.17 & 1 \\
\hline $\begin{array}{c}\text { With single } \\
\text { Pin P1 }\end{array}$ & 6.9 & -20.67 & 7.2 \\
\hline
\end{tabular}

\subsection{EFFECT OF TWO PIN SHORTING}

Shorting an additional Pin (P2) nearer to any of the other vertex (other than $\mathrm{P} 1$ ) results in dual band effect as shown in fig.3a. The two resonant frequencies are $6.03 \mathrm{GHz}$ and $7.238 \mathrm{GHz}$ as shown in fig.3b. The dual band effect can be produced either by LHCP (left hand circular polarization) or RHCP (right hand circular polarization).Both structure produced almost same return loss performance. The corresponding directive gain for both the resonant frequencies is shown in fig. $3 \mathrm{c}$ and fig. $3 \mathrm{~d}$.and comparison is done in table (2).Therefore it can be concluded that dual band can be achieved by using dual pin shorting near the vertices. Where one pin must be shorted on the same axis as of the axis of feed point. 


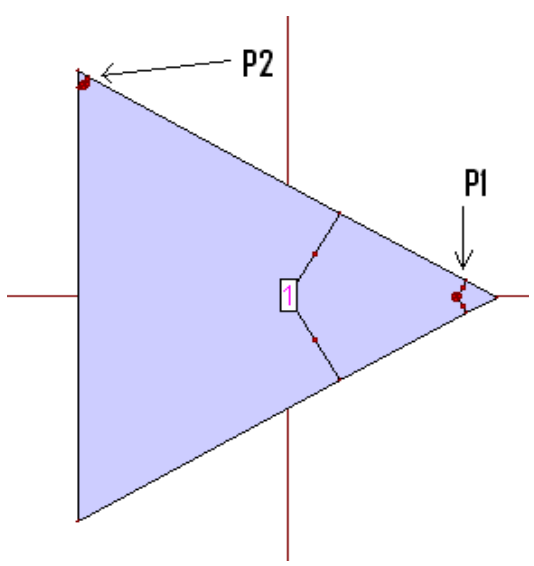

Figure 3a: Effect of dual Pin shorting.

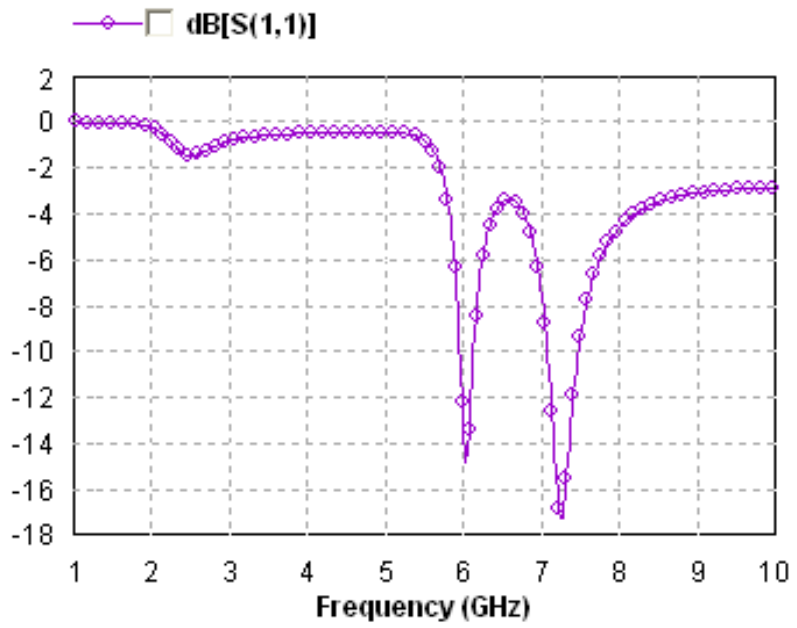

Figure 3b: Return Loss Performance for two pin shorting.
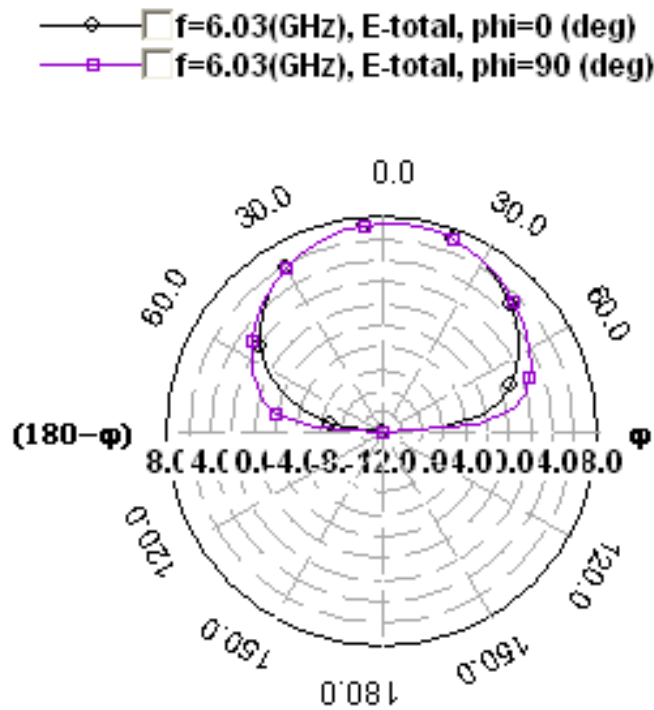

Elevation Pattern Directivity Display (dBi)

Figure3.c: Radiation pattern at $\mathbf{f}_{\mathbf{1}}=\mathbf{6 . 0 3} \mathrm{GHz}$. (For two pin shorting).
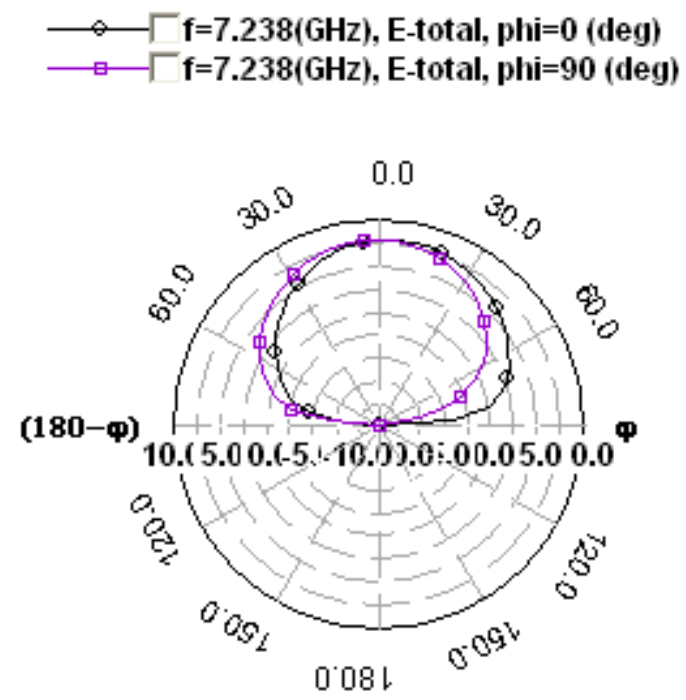

Elevation Pattern Directivity Display

(dBi)

Figure3.d: Radiation pattern at $\mathbf{f}_{2}=7.238$ GHz. (For two pin shorting).

Table: 2

\begin{tabular}{|c|c|c|c|c|}
\hline $\begin{array}{c}\text { Circular } \\
\text { polarization }\end{array}$ & $\mathrm{f}_{1}(\mathrm{GHz})$ & B.W $(\mathrm{GHz})$ & & $\begin{array}{c}\% \\
\mathrm{f}_{2}(\mathrm{GHz})\end{array}$ \\
\hline $\mathrm{LHCP}$ & 6.03 & 2.8 & 7.238 & 5.3 \\
\hline $\mathrm{RHCP}$ & 5.98 & 2.85 & 7.2 & 5.32 \\
\hline
\end{tabular}

\subsection{EFFECT OF TWO PIN SHORTING WITH A CIRCULAR NOTCH}

A circular notch is inserted in between two pin shorted vertices. The proposed length of circular notch $(\mathrm{L})$ is given as $(\lambda / 4)<\mathrm{L}<(\lambda / 2)$. So for the proposed antenna, $\mathrm{L}=13.23 \mathrm{~mm}$ is taken as shown in fig.4a.With circular notch loading, the enhanced bandwidth of $13.42 \%$ with Centre frequency $\left(f_{c}\right)$ of $6.98 \mathrm{GHz}$ is produced, as shown in fig. $4 \mathrm{~b}$ and table (3).The primary resonant frequency $\left(\mathrm{f}_{1}\right)$ is $6.631 \mathrm{GHz}$ and the secondary resonant frequency $\left(f_{2}\right)$ is $7.1398 \mathrm{GHz}$. The corresponding directive gain is shown in fig. $4 \mathrm{c}, 4 \mathrm{~d}$ and $4 \mathrm{e} . \mathrm{No}$ bandwidth enhancement is observed when the values of " $L$ " lie outside the above defined boundary. 


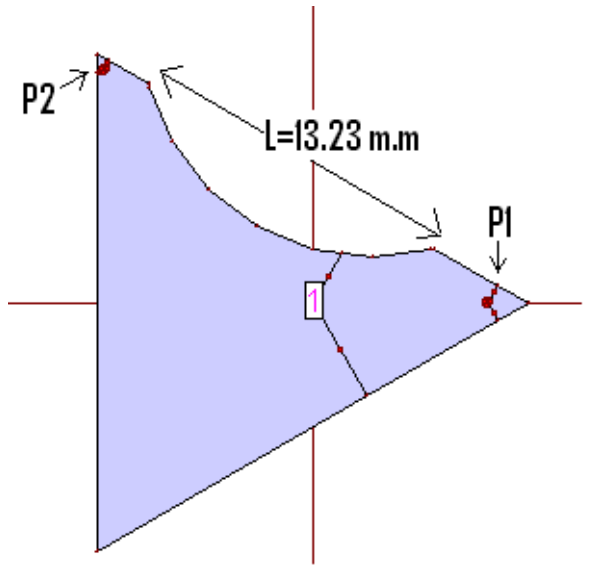

Figure 4a: Effect of two Pin shorting with a circular notch.

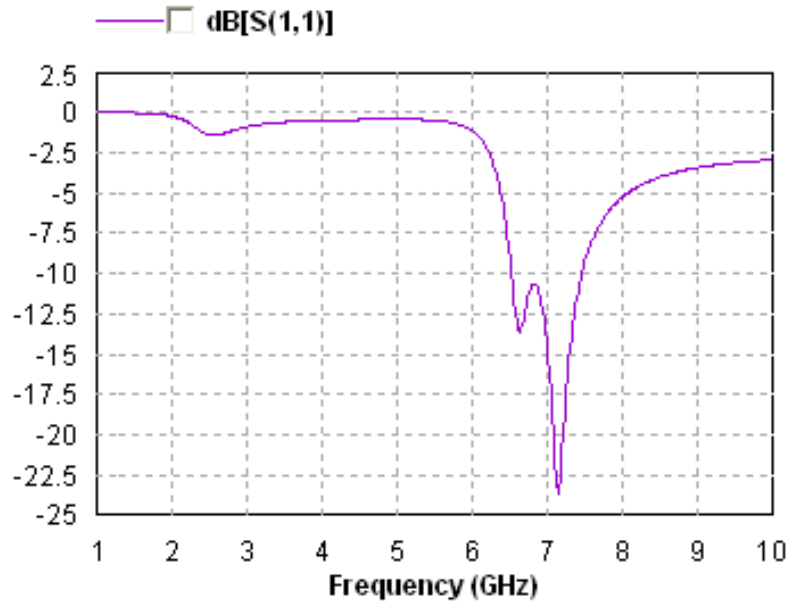

Figure 4b: Return Loss Performance for two pin shorting with a circular notch.
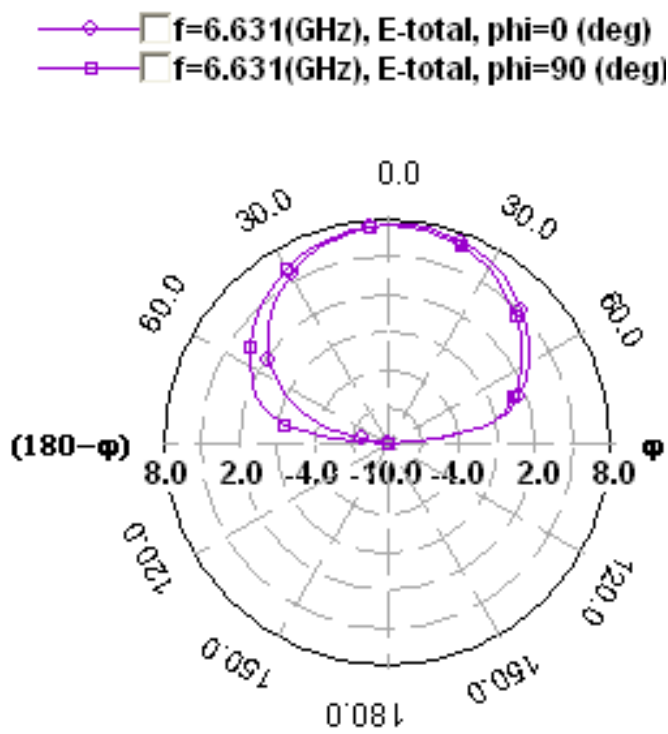

Elevation Pattern Directivity Display (dBi)

Figure4.c: Radiation pattern at $\mathbf{f}_{\mathbf{1}}=\mathbf{6 . 6 3 1} \mathrm{GHz}$. (For two pin shorting with a circular notch).
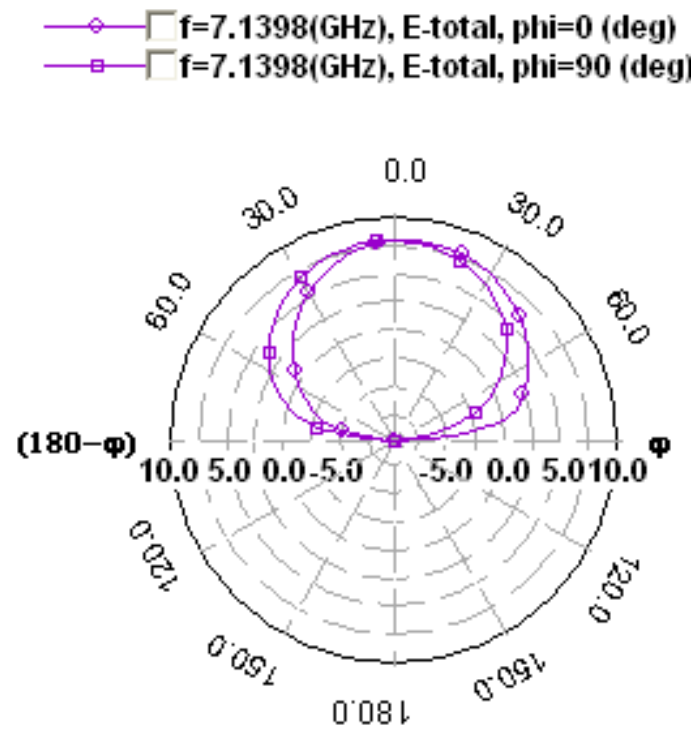

Elevation Pattern Directivity Display (dBi)

Figure4.d: Radiation pattern at $\mathbf{f}_{2}=7.1398 \mathrm{GHz}$. (For two pin shorting with a circular notch).
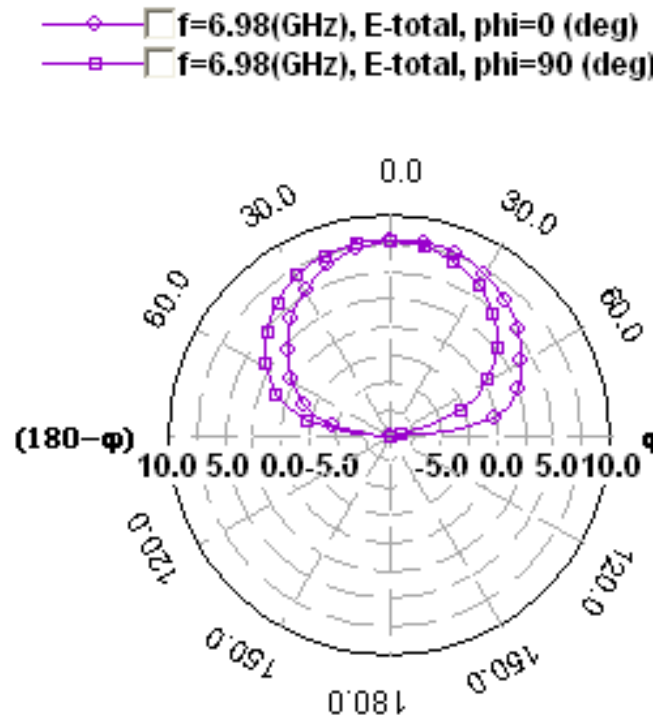

Elevation Pattern Directivity Display (dBi)

Figure4.e: Radiation pattern at $\mathrm{f}_{\mathrm{c}}=6.98 \mathrm{GHz}$. (For two pin shorting with a circular notch).

Table: 3

\begin{tabular}{|c|c|c|c|c|c|}
\hline$f_{1}(\mathrm{GHz})$ & $\mathrm{f}_{2}(\mathrm{GHz})$ & $\mathrm{fc}(\mathrm{GHz})$ & B.W.(GHz) & $\begin{array}{c}\text { Return } \\
\text { loss for } \\
\mathrm{f}_{1}(\mathrm{~dB})\end{array}$ & $\begin{array}{c}\text { Return } \\
\text { loss for } \\
\mathrm{f} 2(\mathrm{~dB})\end{array}$ \\
\hline 6.631 & 7.1398 & 6.98 & 13.42 & -13.8 & -22.94 \\
\hline
\end{tabular}




\section{THE EFFECT OF DIFFERENT DIELECTRICS ON THE BANDWIDTH PERFORMANCE}

The proposed structure is tested on different available dielectric material. The percentage bandwidth degraded sharply for higher value of dielectric $\operatorname{constant}\left(\varepsilon_{\mathrm{r}}\right)$ as thichness(h) is increased as shown in fig.5a.It is also observed that for $\varepsilon_{\mathrm{r}}=3.2$,the $\% \mathrm{~B} . \mathrm{W}$. is almost contant w.r.t thickness.Therefore in the proposed antenna the dielectric constant of substrate is taken as $\varepsilon_{\mathrm{r}}=3.2$.

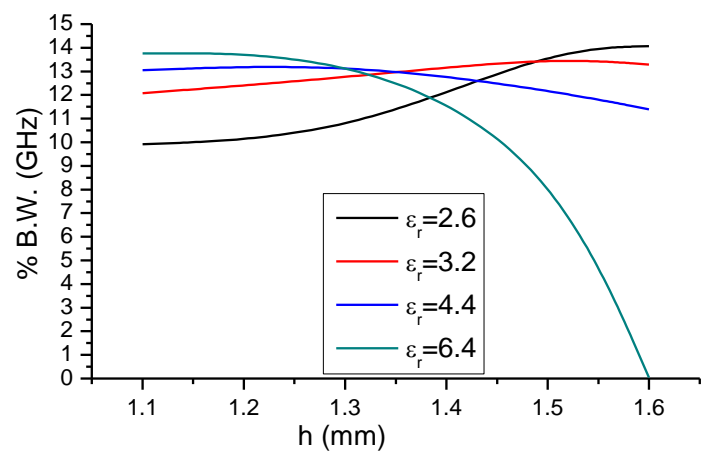

Figure5.a:\%B.W vs. thickness plot for different value of dielectric constant.

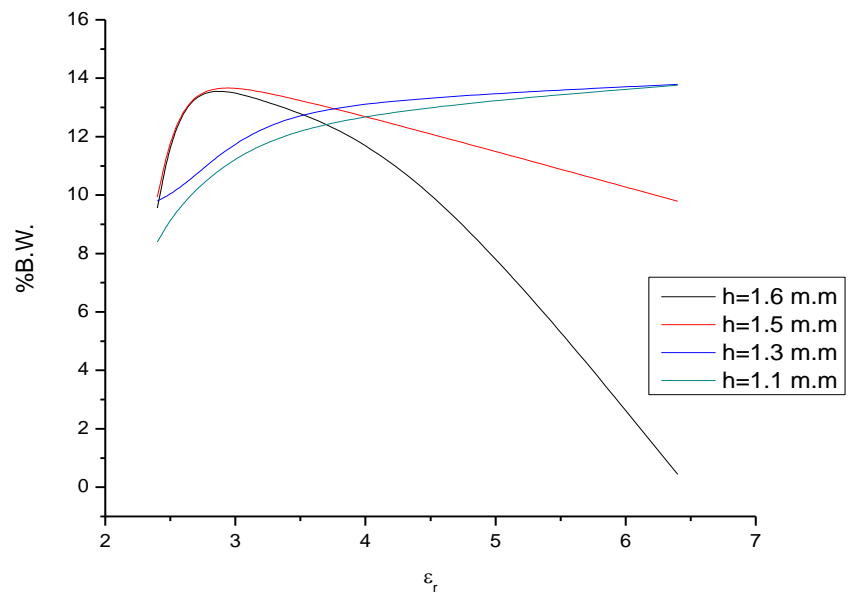

Figure5.b:\%B.W vs. relative permittivity plot for different value of substrate thickness.

\section{DIRECTIVITY}

For the proposed antenna the sufficient directivity (in $\mathrm{dBi}$ ) can be achieved in between the utilized bandwidth from $6 \mathrm{GHz}$ to $8.5 \mathrm{GHz}$ with maximum directivity of $7.85 \mathrm{dBi}$ at $7.4 \mathrm{GHz}$ as shown in fig.6.

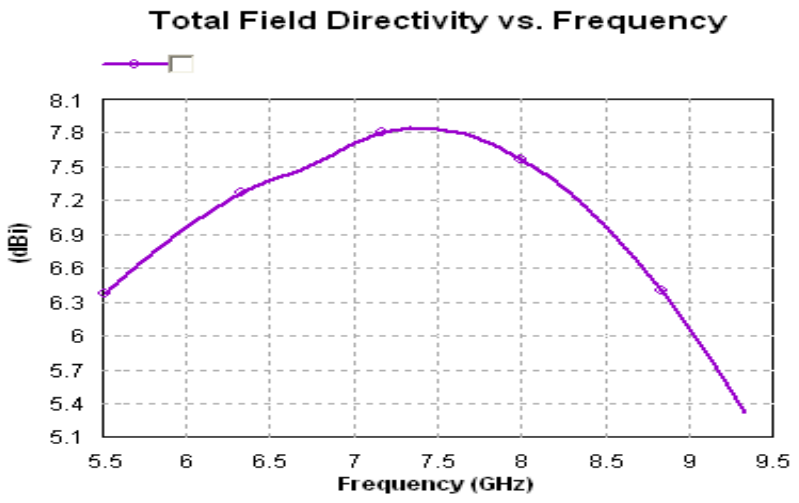

Figure6: Directivity vs. frequency plot for two pin shorted antenna with circular notch.

\section{CONCLUSION}

The simulation carried out on the new proposed antenna. The two pin shorting effect produces dual band and the notch loading along with the two shorting pins results in enhanced bandwidth performance. Bandwidth performance of this antenna is also examined for various antenna parameters such as substrate thickness and substrate permittivity. It is concluded that for higher value of permittivity the percentage bandwidth significantly decreases with increasing thickness.

\section{REFERENCES}

[1] Pozar, D. M. and D. H. Schaubert, Microstrip Antennas: The Analysis and Design of Microstrip Antennas and Arrays, IEEE Press, New York, 1995.

[2] Zhang, Y. P.and J. J. Wang, ITheory and analysis of di®erentially-drivenmicrostrip antennas," IEEE Trans. Antennas Propag., Vol. 54, 1092\{1099, 2006.

[3] S. Sadat, M. Fardis, F. Geran, G. Dadashzadeh, N. Hojjat and M. Roshandel, "A Compact Microstrip Square-Ring Slot Antenna for UWB Applications," IEEE Antennas and propagation Society International Symposium, 9-14 July 2006, pp. 4629-4632.

[4] K. F. Lee, K. M. Luk, K. F. Tong, S. M. Shum, T. Huynk and R. Q. Lee, "Experimental and Simulation Studies of the Coaxially Fed U-slot Rectangular Patch" IEEE Proceedings of Microwave Antenna Propagation, Vol. 144, No. 5, October 1997, pp. 354-358.

[5] Deshmukhet. al., "Multiband Configurations of stubLoaded slotted Rectangular Microstrip Antenna", IEEE Antennas and Propagation Magazine, Vol. 52, No.1 2010.

[6] Y. J. Sung M. Kim, and Y.-S. Kim, "Harmonics Reduction With Defected Ground Structure for a Microstrip Patch Antenna", IEEE Antennas and Wireless Propagation Letters,VOL. 2, 2003.

[7] Matin, M. M., B. S. Sharif, and C. C. Tsimenidis, \Probe fed stacked patch antenna for wideband applications," IEEE Trans. Antennas Propag., Vol. 55, No. 8, 2385\{2388, 2007.5. Wi, S. H., Y. B. Sun, I. S. Song, S. H. Choa, I. S. Koh, Y. S. Lee, and J. G. Yook, IPackageLevel integrated antennas based onLTCC technology," IEEE Trans. Antennas Propag., Vol. 54, No. 8,2190\{2197, 2006.

[8] Zeland Software Inc. IE3D: MoM-Based EM Simulator.[Online]Available: http://www.zeland.com 